The reactions to tartrazine seem to have many features in common with the more frequent reactions to salicylates. Both occur when the urticaria is active, and when patients have been clear for some time they are able to take salicylates and tartrazine without producing weals. Thus these reactions are probably due not to an allergic mechanism but to some pharmacological action. Presumably tartrazine and salicylates have some non-specific effect on the production of metabolites leading to development of the urticarial weals.

The prevalence of reactions to tartrazine in patients with chronic urticaria is about $10 \%$, and once the phase of urticaria has been settled the patients can again take tartrazine without trouble. It would seem that the overall dangers from tartrazine in foods and drugs have been exaggerated, certainly in patients with urticaria.

We thank Beecham Research Laboratories for advice and for providing capsules of tartrazine.

1 Michaelsson G, Juhlin L. Urticaria induced by preservatives and dye additives in food and drugs. $B r \mathcal{F}$ Dermatol 1973;88:525-32.

2 Warin RP, Smith RJ. Challenge test battery in chronic urticaria. $\mathrm{Br} \boldsymbol{f}$ Dermatol 1976;94:401-6.

${ }^{3}$ Moore-Robinson M, Warin RP. Effect of salicylates in urticaria. Br Med f 1967 ;iv :262-4.

4 Juhlin L, Michaelsson G, Zetterstrom O. Urticaria and asthma induced by food and drug additives in patients with aspirin hypersensitivity. $\mathcal{F}$ Allergy Clin Immunol 1972;50:92-8.

5 Warin RP, Smith RJ. Chronic urticaria: investigations with patch and challenge tests. Contact Dermatitis $1982 ; 8: 117-21$.

(Accepted 23 February 1982)

Department of Dermatology, Bristol Royal Infirmary BS2 8HW

ROBERT P WARIN, MD, FRCP, dermatologist

RUTH J SMITH, MB, CHB, clinical assistant in dermatology

\section{Resting pulse rate in marathon runners}

In 1935 McKinlay and Walker ${ }^{1}$ reported a study of resting heart rate undertaken in Glasgow, which was used by Bradford Hill as an example in all editions of Principles of Medical Statistics. It is surprising, therefore, that few subsequent epidemiological studies have included resting heart rate as a variable to predict health or disease.

It is well known that long distance runners have a slow resting heart rate, but we know of no studies reporting more than 50 cases. We measured the resting heart rate of 103 runners in the Cardiff marathon in 1981

\section{Subjects, methods, and results}

Over 3000 people ran in the Cardiff marathon on 20 September 1981, and $95 \%$ completed the run in 146 to 465 minutes. The Western Mail published the names of 2419 of those who took less than 390 minutes to complete the course. We selected three groups: (1) the first $59(<182$ minutes); (2) the 58 placings 943 to 1000 (240-300 minutes); and (3) the last 57 placings (360-390 minutes)

We sent a postal inquiry to 155 of these people with reliable addresses requesting age, sex, height, weight, smoking habits, and resting pulse rate. A total of $118(76 \%)$ responded, of whom 10 were women, five children, and $103 \mathrm{men}$. We report the results for men only.

There were no consistent differences in age or height between the groups. At a standardised height of $173 \mathrm{~cm}$ subjects in group 1 were $4.5 \mathrm{~kg}$ lighter than subjects in group 2 , who were $6.0 \mathrm{~kg}$ lighter than subjects in group 3 . This is in agreement with other reports. ${ }^{2}$ In groups 1 and $25 \%$ were smokers, compared with $26 \%$ in group 3 . The mean $( \pm S D$ ) resting pulse rates (beats/minute) were $51 \cdot 0 \pm 7 \cdot 6$ in group $1 ; 62.6 \pm 8.8$ in group 2 ; and $67.6 \pm 8.7$ in group 3. The differences between group 1 and the two other groups were significant $(p<0.001)$; the difference between groups 2 and 3 was in the same direction and approached significance $(p \simeq 0.05)$. Subjects in group 1 spent 8.7 hours a week in training, in group 26.5 hours, and in group 35.4 hours.

\section{Comment}

Self-reporting of resting heart rate may give rise to inaccuracies. To minimise non-response we did not stipulate how or when it should be recorded, but we understand that trained athletes usually take their resting pulse rate seated first thing in the morning or, if during the day, after 15 minutes' rest. Recording the resting pulse rate is an integral part of training for runners. Our results are consistent with other studies reporting low resting pulse rate associated with physical fitness. Bond ${ }^{3}$ found that five runners of Olympic standard had even lower rates.

The figure compares the three groups with the Olympic runners ${ }^{3}$ and with the Glasgow sample of healthy men. ${ }^{1}$ Although the Glasgow sample was not a valid comparison group, some broad inferences may be drawn. Resting pulse rate declines in athletes subject to training, and this is advantageous to completing a marathon in a low time-the lower the resting pulse rate the shorter the time.

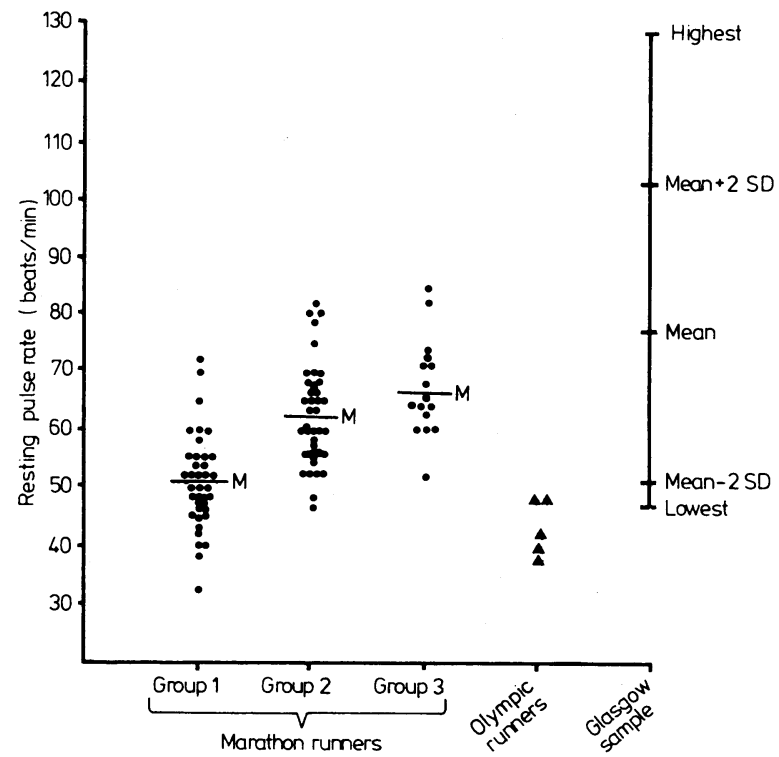

Resting pulse rates in groups of marathon runners and a sample of healthy men in Glasgow.

We consider that resting pulse rate may have a wider relevance to health: 25 deaths occur annually on UK squash courts, ${ }^{4}$ and 67 people died in sauna baths in Finland in one year. ${ }^{5}$ Intense activity, emotion, and mental and thermal stresses may raise heart rates to 200 beats/minute. If 180 beats/minute is a safe submaximal limit then a rate of 90 can only double, whereas a rate of 60 may increase threefold. We suggest that sudden deaths in sport, in saunas, or after stress are more likely in people with higher resting pulse rates.

Clearly, resting pulse rate may be reduced by increasing physical fitness, but it may also be reduced by avoiding smoking. Its importance as an indicator of health, of risk of disease, and of mortality has been neglected in recent epidemiological studies. It deserves more respect and attention.

We thank Mr Tony Barclett, of the Western Mail, for the addresses of the runners, and we thank all the respondents.

Full data and a comprehensive bibliography are available on request.

${ }^{1}$ McKinlay PL, Walker AB. Observations on blood pressure in healthy adult males. Edinburgh Medical fournal 1935;407:42.

2 Milvy P. The marathon: physiological, medical, epidemiological, and psychological studies. Ann NY Acad Sci 1977;301:620-6.

${ }^{3}$ Bond AP. Some distinguishing features between short- and long-distance runners. Undergraduate research project. Cardiff: Department of Community Medicine, Welsh National School of Medicine, Autumn 1973.

4 Fowler AW. Cause of death on squash courts. On Call 1980;14, No 10:7.

5 Taggart P, Parkinson P, Carruthers M. Cardiac responses to thermal, physical, and emotional stress. Br Med $\mathcal{F} 1972$;iii :71-6.

(Accepted 17 February 1982)

Department of Medical Statistics, Welsh National School of Medicine, Cardiff CF4 4XN

T KHOSLA, PHD, senior lecturer

H CAMPBELL, FRCP, FFCM, professor of medical statistics 